\title{
Clinical Trials Supporting the Role of the IL-17/IL-23 Axis in Axial Spondyloarthritis
}

OPEN ACCESS

Edited by:

Dimitrios Petrou Bogdanos, University of Thessaly, Greece

Reviewed by: Erika H. Noss,

University of Washington,

United States

Ana Maria Gamero,

Temple University, United States

*Correspondence:

Carlo Selmi

carlo.selmi@humanitas.it

${ }^{\dagger}$ These authors have contributed equally to this work

Specialty section:

This article was submitted to Cytokines and Soluble Mediators in Immunity, a section of the journal

Frontiers in Immunology

Received: 29 October 2020 Accepted: 14 May 2021

Published: 02 June 2021

Citation:

Ceribelli A, Motta F, Vecellio M, Isailovic N, Ciccia Fand Selmi C (2021)

Clinical Trials Supporting the Role of the IL-17/L-23 Axis in Axial Spondyloarthritis.

Front. Immunol. 12:622770. doi: 10.3389/fimmu.2021.622770

\author{
Angela Ceribelli ${ }^{1,2}$, Francesca Motta ${ }^{1,2}$, Matteo Vecellio $^{1,3}$, Natasa $_{\text {Isailovic }}{ }^{1}$, \\ Francesco Ciccia ${ }^{4+}$ and Carlo Selmi ${ }^{1,2 * t}$ \\ ${ }^{1}$ Division of Rheumatology and Clinical Immunology, Humanitas Clinical and Research Center - IRCCS, Rozzano (Mi), Italy, \\ 2 Department of Biomedical Sciences, Humanitas University, Rozzano (Mi), Italy, ${ }^{3}$ Nuffield Department of Orthopaedics, \\ Rheumatology and Musculoskeletal Sciences, University of Oxford, Oxford, United Kingdom, ${ }^{4}$ Università degli Studi della \\ Campania Luigi Vanvitelli, Naples, Italy
}

The term spondyloarthritis (SpA) encompasses a heterogeneous group of inflammatory musculoskeletal diseases with several common genetic background and clinical features, including the possible involvement of the axial skeleton with peripheral mono- or oligoarthritis and frequently coexisting skin, eye and intestinal manifestations. When the sacroiliac joints or other parts of the spine or thoracic wall are predominantly affected at magnetic resonance or X-ray imaging with inflammatory back pain, the disease is classified as axial SpA and the therapeutic choices are significantly different compared to cases of peripheral arthritis. Moving from the narrow effectiveness and safety profiles of non-steroidal anti-inflammatory drugs, there has been a significant research effort aimed at identifying new treatments based on our better understanding of the pathogenesis of SpA. Indeed, in parallel with the solid data demonstrating that IL-17 and IL-23 are key cytokines in the development of enthesitis and spondylitis, monoclonal antibodies interfering with this pathway have been developed for the treatment of axial SpA. Furthermore, the IL-17/IL-23 axis is key to extra-articular manifestations such as inflammatory bowel disease, uveitis, and psoriasis which are frequent comorbidities of SpA. Currently available drugs act through these mechanisms recognizing IL-23 and targeting IL-17, such as secukinumab and ixekizumab. These therapeutic approaches are now envisioned in the international treatment recommendations for psoriatic arthritis with an axial phenotype as well as for ankylosing spondylitis (AS). We will provide herein a concise comprehensive overview of the clinical evidence supporting the use of these and other drugs acting on IL-23 and IL-17 in axial SpA.

Keywords: Th17, enthesitis, spondylitis, biologics, HLA B27 allele 


\section{INTRODUCTION}

The role of interleukin (IL)-17 and IL-23 in the pathogenesis of chronic inflammatory diseases such as spondyloarthritis (SpA) has been widely investigated over the past two decades, and this knowledge has led to the development of targeted therapies (1). IL-17 was first described in 1996 due to its effect on the production of IL- 6 and IL-8 by rheumatoid arthritis (RA) synoviocytes (2) and the new cytokine was first named IL-17A but several other members of the family were subsequently identified, in particular IL-17F, which is approximately $50 \%$ homologous to IL-17A and both converge on TNF $\alpha$, among other mediators $(3,4)$.

IL-23 induces IL-17A, IL-17F, IL-21 and IL-23 production (5, 6) thus playing an important role in the Th17 cell-mediated responses. IL-23 is part of the family of IL-12 cytokines and IL-12 and IL-23 share a common p40 subunit, coupled with a p35 chain for IL-12 and a p19 chain for IL-23 (7). IL-17 is a product of T cells, particularly Th17, even though several other cell types are able to produce IL-17, such as CD8+ T cells, $\gamma \delta \mathrm{T}$ cells, type 3 innate lymphoid cells (ILC3s) and natural killer T cells $(8,9)$. Other cell types such as neutrophils and mast cells do not express IL-17 mRNA but they can store exogenous IL-17 $(10,11)$. On the other hand, both IL-12 and IL-23 are produced by antigenpresenting cells, in particular dendritic cells, monocytes and macrophages, and based on the predominant presence of these cells in the inflamed tissues we can predict how the contribution of IL-23 is significant in a specific disease $(5,7)$ (Figure 1).

Both IL-23 and IL-17 have shown a significant therapeutic effect first in animal models and subsequently in patients affected by rheumatic conditions such as axial SpA (axSpA), i.e. a form of $\mathrm{SpA}$ that predominantly affects the axial skeleton, ranging from sacroiliitis to paradigmatic AS $(1,12)$. In particular, IL-17 inhibitors are currently approved as biological disease-modifying anti-rheumatic drugs (DMARDs) for axSpA, together with TNF $\alpha$ inhibitors, and currently include secukinumab [a human IgG1 $\kappa$ monoclonal antibody that binds to IL-17A (13)], ixekizumab [a humanized monoclonal antibody anti-17A (14)], while bimekizumab [a humanized monoclonal antibody anti-17A and IL-17F (15)] and netakimab [a humanized monoclonal antibody targeting interleukin-17A (16)] are being evaluated. On the other hand, IL-12/IL-23 inhibitors are effective against psoriasis $(\mathrm{PsO})$ and psoriatic arthritis (PsA), predominantly on peripheral synovitis and enthesitis in $\operatorname{axSpA}(1)$, while the efficacy on axial manifestations remains inconclusive.

All biologic therapies currently approved for the treatment of axSpA are included in the recent recommendations approved in 2019 by the American College of Rheumatology, Spondylitis Association of America and Spondyloarthritis Research and Treatment Network (17), which strongly recommend to treat adult patients with active AS despite TNF $\alpha$ inhibitor (primary non-responder) with secukinumab or ixekizumab, while IL17 inhibitors are not recommended in the presence of inflammatory bowel disease (IBD) or recurrent uveitis.

In this concise review we will discuss the available clinical trials data and the recent advances in the discovery of new therapies for axSpA, with a specific focus on therapies targeting the IL-17/IL-23 axis.

\section{CLINICAL TRIALS IN AXSPA FOR AVAILABLE DRUGS TARGETING THE IL-17A/IL-23 AXIS}

In the last 5 years, new therapies for the treatment of axSpA have been approved thanks to the significant positive results in efficacy and safety obtained by these therapies targeting the IL-17/IL23 axis.

\section{Anti IL-17A Drugs}

Two anti-IL-17A monoclonal antibodies, secukinumab and ixekizumab, are currently approved for the treatment of axSpA.

Secukinumab was initially approved for $\mathrm{PsO}$ treatment, later for PsA and axSpA. It was demonstrated that, compared with placebo, a significantly higher percentage of patients with active PsA achieved a 20\% improvement in the American College of Rheumatology response criteria (ACR20) at week 24 when treated with secukinumab $(18,19)$. It provided a valid treatment for PsA entheseal disease (20), and was effective for signs and symptoms of axial disease in PsA and SpA patients. MAXIMISE evaluated the efficacy and safety of secukinumab (at the dosage of 300 and $150 \mathrm{mg}$ ) in managing the axial manifestations of PsA, and results showed a rapid and significant improvement in ASAS20 responses at week 12 for axial manifestations and inadequate responses to NSAIDs (21) (ClinicalTrials.gov Identifier: NCT02721966). More recently, secukinumab proved efficacious for the treatment of nonradiographic axSpA (US FDA, June 2020) based on the results obtained from the PREVENT clinical trial (ClinicalTrials.gov Identifier: NCT02696031). By further searching the site clinicaltrials.gov for interventional studies in phase III aimed at blocking IL-17 in axSpA, we retrieved 7 studies focused on the use of secukinumab, for the analysis on the benefit of this drug on symptoms such as pain and on its safety in a 3-year follow-up period. One of these trials is focused on the speed of secukinumab-induced relief from pain in patients with axSpA (SKIPPAIN trial, ClinicalTrials.gov Identifier: NCT03136861), and its action on specific clinical manifestations such as axial involvement. Besides evaluating the efficacy of this drug, also its safety and tolerability are under evaluation for a follow-up period up to 3 years after marketing secukinumab.

Ixekizumab demonstrated efficacy for the treatment of moderate to severe plaque $\mathrm{PsO}$ since 2016. The indication was approved in 2017 for PsA, based on the reported ACR20 in a higher proportion of patients when compared with placebo (22) and showing efficacy also on entheseal disease (23). In 2019 it was approved for active radiographic axSpA thanks to its efficacy and safety outcome results $(24,25)$. More recently, ixekizumab was evaluated in the COAST-X trial in non-radiographic axSpA patients and it showed superiority to placebo at weeks 16 and 52, with similar rate of adverse events compared with previous ixekizumab studies. Results show that ixekizumab may be a 


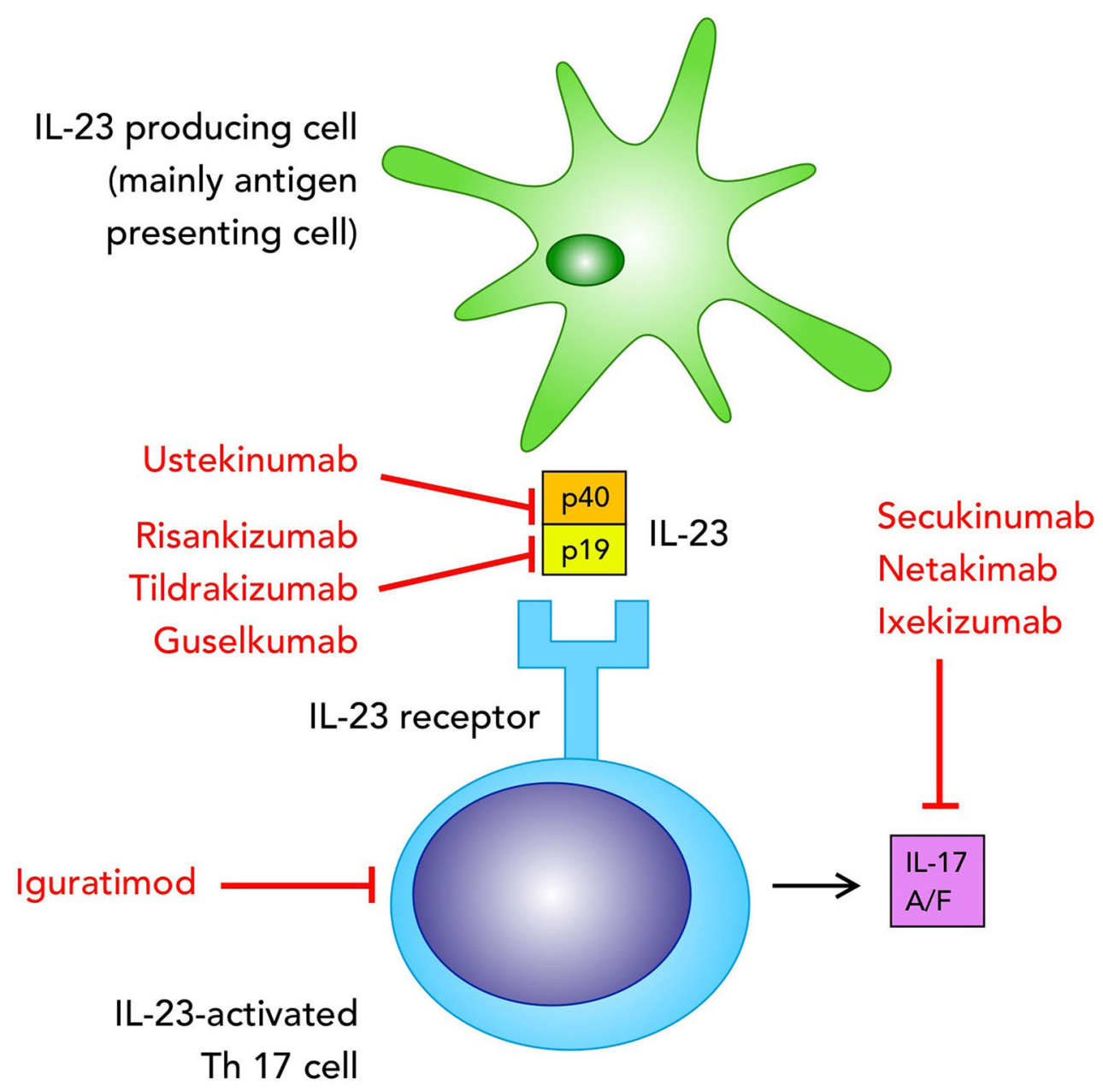

FIGURE 1 | Biologics targeting the IL-23/L-17 pathway in axial spondyloarthritis, currently used in clinical practice or tested in clinical trials mentioned in the text.

therapeutic option for patients with non-radiographic axSpA who did not respond significantly or were intolerant to NSAIDs $(24,26)$, and this led to the U.S. FDA approval for the treatment of non-radiographic axSpA in June 2020.

Netakimab (BCD-085) is a novel molecule currently in phase III clinical trials in axSpA patients. In a Phase I clinical trial (ClinicalTrials.gov Identifier: NCT02380287), netakimab was evaluated for pharmacokinetics and safety in healthy volunteers, and results reported in October 2015. Thanks to the data from the Phase I trial, a randomized, placebo-controlled, double-blind Phase II trial (ClinicalTrials.gov Identifier: NCT02763111) was started to evaluate safety, effectiveness, and pharmacokinetic profile in 89 men and women with SpA. This drug was tested at doses of $40 \mathrm{mg}, 80 \mathrm{mg}$, or $120 \mathrm{mg}$ for 12 weeks and the trial results showed significant improvements in AS assessment score (ASAS), plus adverse events, withdrawal symptoms, and drug concentration. The results of this phase II trial (16) showed that netakimab was effective and generally safe in SpA patients, thus it was followed by the multicenter, randomized, placebo-controlled Phase III clinical trial (ClinicalTrials.gov Identifier: NCT03447704) which evaluated the safety and effectiveness of netakimab $120 \mathrm{mg}$ against a placebo, for up to one year, in 228 patients with active SpA. Netakimab has been registered in spring 2020 for treatment of SpA and PsA in Russia. According to the Phase III clinical study BCD-085-5/ASTERA, $40 \%$ of patients with SpA achieve an ASAS40 response after 16 weeks of therapy (27).

A recent publication by Mease et al. showed the results of two phase III trials (AMVISION-1 and AMVISION-2) on the efficacy and safety of brodalumab, an IL-17 receptor subunit A inhibitor, compared with placebo, in patients with PsA (28). Results show that brodalumab confers a rapid and significant improvement in signs and symptoms of PsA versus placebo and it has a tolerance and safety profile similar to other IL-17 inhibitors (28).

Iguratimod (IGU), a novel small molecule with the effect similar to a non-steroidal anti-inflammatory drug and diseasemodifying anti-rheumatic drug, acts through various 
mechanisms such as inhibition of prostaglandin E2, TNF $\alpha$, IL-17 production, macrophage migration inhibitory factor (MIF)induced proinflammatory effects, osteoclastogenesis, and it promotes osteoblastic differentiation. IGU may be an effective treatment for axSpA as its mechanisms of action are related to those involved in the pathogenesis of axSpA, as shown in several small-scale clinical trials (29). IGU may be a suitable treatment for $\operatorname{axSpA}$ as clinical trials demonstrate a significant improvement for the ASAS20 response and reduction in inflammatory biomarkers in patients receiving IGU $(29,30)$.

\section{Anti IL-23 Drugs}

Ustekinumab, a human IL-12 and IL-23 antagonist that binds to their p40 subunit so that they subsequently cannot bind to their receptors to trigger pro-inflammatory cytokine release, is currently approved for use in moderate-severe $\mathrm{PsO}, \mathrm{PsA}$ and Crohn's disease, while its efficacy in the treatment of axSpA was not demonstrated in 3 placebo-controlled trials, although its safety profile was consistent with studies in other indications (31). More recently, ustekinumab has been evaluated for the use in adult patients affected by moderate-severe ulcerative colitis, while its use failed in other autoimmune diseases such as multiple sclerosis (32), and encouraging data were provided in systemic lupus erythematosus.

Guselkumab, a monoclonal antibody targeting the IL-23 subunit alpha (p19 subunit) currently approved for the use in plaque $\mathrm{PsO}$, is under evaluation for the use also in PsA with significant improvement in particular for manifestations such as enthesitis and dactylitis (33). The results of two phase III, randomized, double-blind, placebo-controlled studies (DISCOVER-1 and -2) on the efficacy of guselkumab in active PsA patients showed a significant improvement of the disease with ACR achievement over 24 weeks $(34,35)$.

Risankizumab is a monoclonal antibody that binds the p19 subunit of IL-23 and demonstrated efficacy in PsO and active peripheral PsA in preapproval trials (36), while a phase II study in axSpA did not show statistical difference from placebo and for this reason the further development of risankizumab in axSpA was not continued (37).

In February 2020, tildrakizumab, a monoclonal antibody targeting the IL-23 p19 subunit, was approved in Italy for treatment of severe plaque $\mathrm{PsO}$ thanks to the significantly positive results obtained in the reSURFACE 1 and 2 trials $(22,23)$. Efficacy and safety of tildrakizumab is under evaluation also for the treatment of active AS or non-radiographic axSpA (ClinicalTrials.gov Identifier: NCT 02980705). A phase II trial based on the use of tildrakizumab, is currently ongoing and results are still being analyzed, but the failure of two previous studies in axSpA with drugs with similar mechanism of action raises doubts these ongoing studies will be successful for treatment in $\operatorname{axSpA}(38)$.

Clinical trials focused on the inhibition of IL-23/IL-17 have been fundamental in $\mathrm{PsO}$, while they showed mixed results in PsA and were even less conclusive in axSpA (39) (Table 1 summarizes IL-17/IL-23 blocking molecules studied in clinical trials for the treatment of axSpA. Figure 1 for their mechanisms of action). These results may mean that we still need to improve our knowledge of $\mathrm{SpA}$, in particular for its pathogenesis, thus further head-to-head studies and more subtle evaluations of local tissue-specific mechanisms are required.

\section{CLINICAL TRIALS IN AXSPA FOR AVAILABLE DRUGS TARGETING IL-17F}

IL-17A shares a structural homology with IL-17F (55\%) and has been reported to perform a similar biological function. Depending on the nature of the responder cell, the ligation of IL-17R triggers signaling pathways causing the activation of the transcription factors $\mathrm{NF \kappa B}, \mathrm{I} \kappa \mathrm{B} \zeta, \mathrm{AP} 1$ and $\mathrm{C}-\mathrm{EBP}$, which induce transcription of several tissue-specific genes (40). However, recent studies have shown that IL-17F forms a homodimeric complex with receptor IL-17RC driving IL-17RA-independent and therefore (IL-17A-independent) signaling (41). The real distribution of the two IL-17RA and IL-17RC receptors on the surface of the cellular actors involved in the pathogenesis of AS is not clear, but it appears likely that some cell types may overexpress IL-17RC compared to IL-17RA, which could make IL-17F signaling through the symmetrical IL-17RC complex more relevant in some patients. Evidences that IL-17F is also increased in psoriatic skin and synovial cells of patients with peripheral SpA (42), support the rationale for targeting IL-17F as a therapeutic strategy as well.

In a recent phase IIb, randomized, double-blind, placebocontrolled, dose-ranging study, the efficacy of dual neutralisation of IL-17A and IL-17F with bimekizumab in patients with active AS has been studied. At week 12, significantly more bimekizumab-treated patients achieved ASAS40 vs placebo with a significant dose-response. At week 48, 58.6\% and $62.3 \%$ of patients receiving bimekizumab 160 and $320 \mathrm{mg}$ throughout the study achieved ASAS40, respectively with similar ASAS40 response rates being observed in re-randomized patients. Although these data are absolutely promising, they are not very different from the single inhibition of IL-17A as can be assumed from a theoretical point of view (34). Greater precision in patient selection, trivially assessing the peripheral distribution of IL-17RA and IL-17RC receptors, could increase the percentage of responders. However, further studies are required to determine the impact of double inhibition, IL-17A and IL-17F on the progression of radiographic progression in AS patients.

\section{OTHER MECHANISMS OF ACTION IN AXSPA THERAPIES}

A detailed discussion of the clinical efficacy of anti-TNF $\alpha$ goes beyond the aims of the present review article. The current recommendations for AxSpa and PsA include this class of drugs on the same line as other mechanisms of action and based on this TNF inhibitors will be mentioned as comparators, as shown in Table $2(43,44)$. 
TABLE 1 | Molecules blocking the IL-17/L-23 axis, studied for the treatment of axSpA.

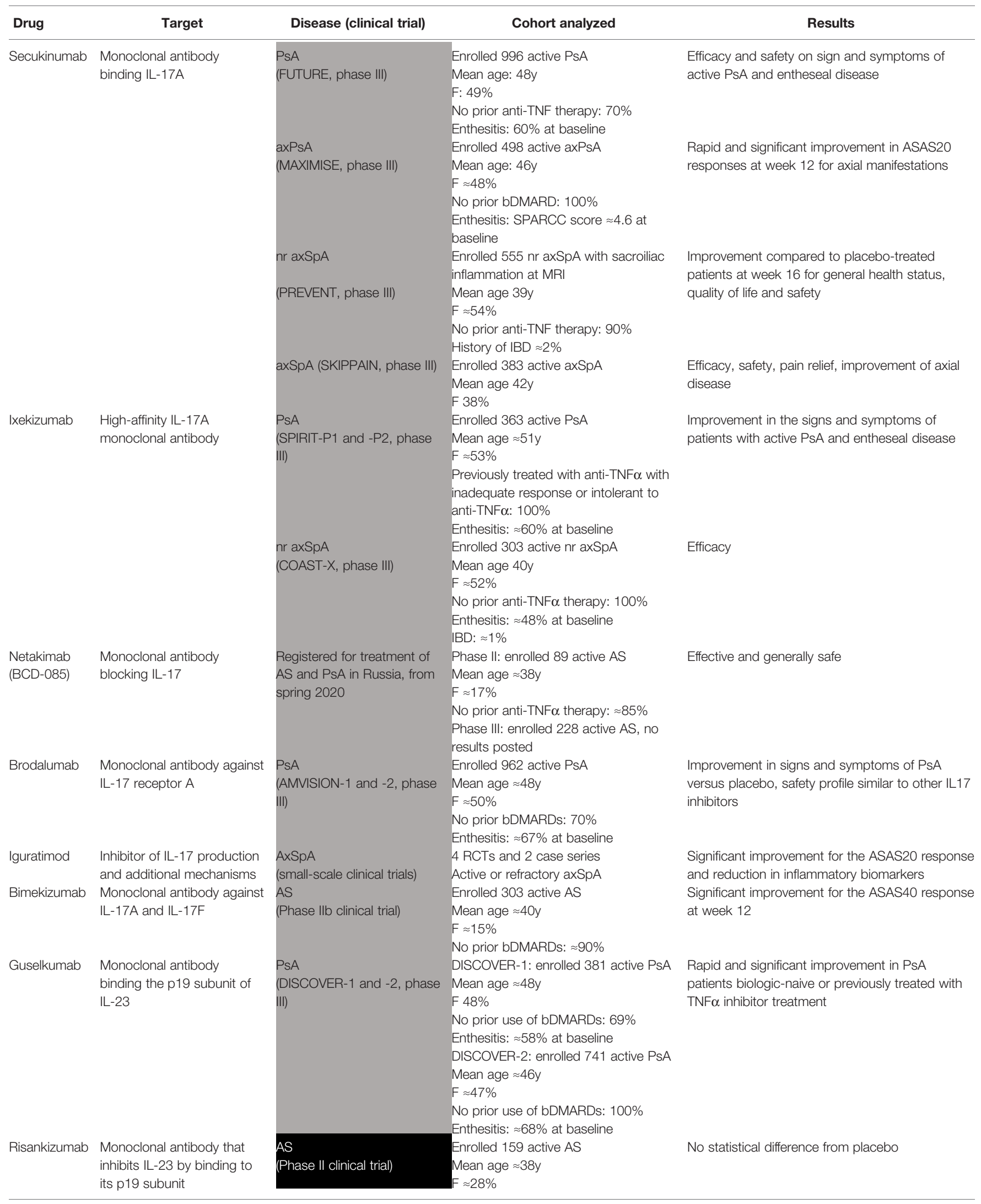


TABLE 1 | Continued

\begin{tabular}{|c|c|c|c|c|}
\hline Drug & Target & Disease (clinical trial) & Cohort analyzed & Results \\
\hline Ustekinumab & $\begin{array}{l}\text { Monoclonal antibody } \\
\text { blocking the } \mathrm{p}-40 \text { subunit of } \\
\text { IL-12/IL-23 }\end{array}$ & $\begin{array}{l}\text { AxSpA } \\
\text { (Phase III clinical trials) }\end{array}$ & $\begin{array}{l}\text { No prior use of bDMARDs: } 100 \% \\
\text { Enrolled } 1018 \text { active AS and } \mathrm{nr} \text { axSpA } \\
\text { Mean age } \approx 38 \mathrm{y} \\
\mathrm{F} \approx 73 \%\end{array}$ & No demonstration of efficacy \\
\hline Tildrakizumab & $\begin{array}{l}\text { Monoclonal antibody that } \\
\text { inhibits IL-23 by binding to } \\
\text { its p19 subunit }\end{array}$ & $\begin{array}{l}\text { AS, nr axSpA } \\
\text { (Phase lla clinical trial) }\end{array}$ & $\begin{array}{l}\text { No prior use of bDMARDs: } 100 \% \text { in } \\
\text { studies } 1 \text { and } 2,88 \% \text { in study } 3 \text {. } \\
\text { Enrolled } 180 \text { active AS or nr axSpA } \\
\text { Mean age } 39 y \\
F \approx 23 \%\end{array}$ & $\begin{array}{l}\text { Failure of two previous studies with drugs with } \\
\text { similar mechanism of action; efficacy and safety } \\
\text { under evaluation in SpA }\end{array}$ \\
\hline
\end{tabular}

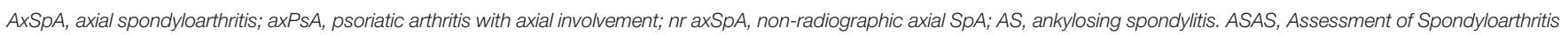
international Society. SPARCC, Spondyloarthritis Research Consortium of Canada enthesitis index. DMARD, disease-modifying anti-rheumatic drug. $y$, years. F, female.

In light gray, effective drugs; in black, non effective drugs; in dark gray, ongoing study.

Besides the anti-TNF $\alpha$ therapies approved in the last 20 years for the treatment of SpA patients (45-47), with proved efficacy also for the treatment of extraarticular manifestations such as uveitis (RAPID-axSpA ClinicalTrials.gov Identifier: NCT01087762) (48), biosimilars of TNF $\alpha$ inhibitors have become increasingly used, and observational studies of biologics-naive patients with SpA have shown similar response and safety in patients treated with originators versus biosimilars, indicating comparable effects in clinical practice (49).

Oral small molecules targeting specific pro-inflammatory intracellular pathways are currently used in conditions such as PsA, as in the case of the phosphodiesterase 4 inhibitor apremilast, and the Janus kinase (JAK) inhibitors tofacitinib and baricitinib, plus filgotinib and upadacitinib still in development for PsA. The rationale for the use of JAKinibs in AS derives from studies in experimental models that have demonstrated a key role of the JAK/ STAT pathway in the pathogenesis of the disease $(50,51)$. Moreover, ex vivo data also demonstrated the ability of several JAK inhibitors to inhibit Th17 responses in patients with AS. The potential efficacy of JAKinibs in the treatment of axial SpA is supported by recent phase II and III clinical trials. Tofacitinib, a JAK1 and 3 inhibitor, was tested in a phase II study in 208 AS patients (52). The ASAS20 response at week 12 occurred in 63\%, $67 \%$, and $40 \%$ in the tofacitinib 5 and $10 \mathrm{mg}$ arms and placebo, respectively, and reduction of inflammation measured by MRI was demonstrated. The phase III study in AS is currently ongoing (ClinicalTrials.gov Identifier: NCT03502616). Upadacitinib, a selective JAK-1 inhibitor, has been also studied in AS patients with active disease and an inadequate response or contraindication to non-steroidal anti-inflammatory drugs in a double-blind, randomised controlled phase 3 trial, the SELECT-Axis study 1 . In this study, significantly more patients in the upadacitinib group reached a higher ASAS40 response compared to placebo group at week 14 (52\% vs 26\%) (53). The TORTUGA study evaluated the efficacy of another selective JAK-1 inhibitor, filgotinib, in patients with AS (54). In this study, at week $12,76 \%$ of patients receiving filgotinib achieved an ASAS20 response compared with $40 \%$ of patients assigned to placebo. ASAS40 was achieved by $38 \%$ patients assigned to filgotinib and by $19 \%$ patients assigned to placebo. Based on these studies, JAK blockade could represent a valid future therapeutic strategy in patients with AS.

\section{DISCUSSION}

From a pathological point of view, IL-23 is a crucial cytokine in the onset of disease manifestations such as enthesitis that may characterize peripheral manifestations in axSpA, as demonstrated by the fact that IL-23 is sufficient to induce the development of enthesitis and entheseal new bone formation in

TABLE 2 | Comparison of different biologic class efficacy in rheumatic diseases and disease subtypes.

\begin{tabular}{|c|c|c|c|c|c|}
\hline & Anti-TNF $\alpha$ & Anti-IL-17 & Anti-IL-23 & JAK inhibitor & PDE4 inhibitors \\
\hline RA & + & - & - & + & - \\
\hline AxSpA & + & + & - & Ongoing studies & - \\
\hline \multicolumn{6}{|l|}{ Disease activity } \\
\hline Radiographic progression & + & + & - & Ongoing studies & - \\
\hline PsA & + & + & + & + & + \\
\hline Enthesitis & + & + & + & + & + \\
\hline Peripheral arthritis & + & + & + & + & + \\
\hline Dactylitis & + & + & + & + & + \\
\hline Axial manifestations & + & + & - & Ongoing studies & - \\
\hline Psoriasis & + & + & + & - & + \\
\hline Nail & + & + & + & - & + \\
\hline IBD & + & - & + & + & - \\
\hline Acute anterior uveitis & + & - & - & - & - \\
\hline
\end{tabular}

AxSpA, axial spondyloarthritis; IBD, inflammatory bowel diseases; RA, rheumatoid arthritis; PsA, psoriatic arthritis; PsO, psoriasis. 
the initial complete absence of synovitis (55). IL-23 stimulates the survival and expansion of Th-17 cells through the receptor IL-23R expressed by uncommitted CD4 and CD8 negative T cells, and this induces the related downstream signaling pathway crucial for the onset of Th-17-mediated diseases like PsA and axSpA (56).

Consistent with these mechanistic models, IL-17 inhibitors showed efficacy in axSpA treatment $(13,14)$ and case-control genome-wide-association studies demonstrated that an IL-23R polymorphism is associated with $\mathrm{SpA}$ (57). Moreover, the overexpression of IL-23 in mice can trigger a form of enthesitis which is similar to enthesitis observed in SpA patients (55). Therefore, it was unexpected to observe the results of two placebo-controlled trials in SpA showing that ustekinumab (31) and risankizumab (37) had no significant improvement on disease activity.

Inconclusive data from trials on IL-23 inhibitors may have several explanations, such as still unknown mechanisms of disease, different molecular effects compared to IL-17 blockers or confounding factors in the design of clinical trials, as heterogeneous enrollment with differences in the composition of the clinical cohorts where the monoclonal antibodies are being investigated (shown in Table 1). A possible additional mechanism of action of IL-17 and IL-23 involves bone metabolism, which is a pivotal pathogenic pathway in axSpA, related to inflammation. As for IL-17A, it has a potential effect on osteoblast differentiation that may depend on the cell type exposed, the differentiation stage of that cell and the timing and duration of cytokine exposure. On the contrary, IL-23 does not seem to have an effect on osteoblast activation (58).

Another difference in the molecular effects of the two cytokines is related to the timing, as IL-23 is thought to play a role in the early stages, making its blocking ineffective in established and symptomatic disease. In murine models the presence of IL-23 induced the conversion of non-pathogenic Th17 into pathogenic Th17 cells, an effect still to be well analyzed in humans (58).

The hypothesis of a non-linear relationship and an uncoupling of IL-23 and IL-17 can also be inferred from Crohn's diseases management, where IL-23 inhibition has some efficacy, while IL-17 blockade can worsen the outcomes.

A deeper knowledge of the IL-17/IL-23 axis should be pursued, as it appears to be one of the main pathways involved in the development of axSpA. In fact, several therapies currently used in conditions such as RA have not demonstrated efficacy in axSpA, as in the case of IL- 1 or IL- 6 inhibitors, T-cell modulators and B-cell ablators. Furthermore, apremilast, introduced in the recommendation for the management of peripheral PsA (43) was tested for active AS in a small proof-of-concept study (59), showing improvement of BASDAI in the treatment versus placebo arm, but the phase III trial failed to discriminate between treated and placebo patients (POSTURE study, ClinicalTrials.gov Identifier: NCT01583374). These results show that it is not enough to reduce inflammation in synovial tissues by using unspecific drugs, and that immunomodulatory agents do not all reach the target to reduce inflammation, in particular in a condition such as axSpA which involves many immunologic pathways in different anatomical areas and where inflammation is related to bone formation in specific sites. Additional chronic autoimmune diseases related to axSpA, such as PsA and IBD- related arthritis are currently evaluated to identify new therapeutic pathways and targets that may lead to disease remission.

Another significant aspect that we may consider for trials results analysis is that AS and axial PsA may be two different diseases with overlapping features rather than entities on the spectrum of the same disease $(60,61)$. In fact, AS patients with or without $\mathrm{PsO}$ seem to be consistently different from axSpA patients when it comes to their demographic features (15 years younger at their first manifestation of arthritis and first presented to the clinic 7 years earlier), genetic predisposition (much higher male predominance and four times more likely to be HLA-B27 positive), clinical characteristics (worse axial disease in AS versus axial PsA, whereas axial PsA has worse peripheral arthritis than AS patients) and radiographic alterations (worse grade of sacroiliitis on radiographs).

These aspects are crucial in the planning of clinical trials, when defining the population of patients to be included, as it may influence the results of specific treatments.

When choosing the biologic therapies for SpA patients, IL-17 inhibitors have always raised concern over the risk of IBD onset. In fact, the clinical development of secukinumab for Crohn's disease was stopped after a small sample size proof-of-concept study because of a higher rate of adverse events including relapse of pre-existing or new onset of IBD (62), and similarly in the phase-2 trial with brodalumab (63). The concern over elevated risk of IBD onset or worsening was minimized in a recent pooled safety analysis of 21 randomised-controlled trials plus post-marketing safety data (2014-2017) with secukinumab, across all rheumatological indications. This analysis reported an exposure adjusted incidence rate of IBD of $<0.1-0.4 / 100$ person-years consistent with the background expected range of incidence rates for these patients (64-66). In conclusion, clinical trials have so far demonstrated the efficacy of anti-IL-17 therapies for axSpA treatment but data on IL-23 blocking remain to be elucidated after the earlier negative findings. This may be due to several reasons, such as the unique immunopathological microenvironment of axSpA, with IL-17 secretion in the absence of IL-23, at least in established disease. Another possible reason may be that many cell types different from conventional $\mathrm{T}$ cells can produce IL-17 in axSpA patients, partially independent of IL-23, and this should be extensively investigated. Currently, IL-17 and TNF $\alpha$ inhibitors are the only effective targeted therapies for axSpA and additional treatments need further testing in clinical trials to assess their efficacy and safety in axSpA.

\section{AUTHOR CONTRIBUTIONS}

AC and FM contributed to data collection and review organization. NI and MV contributed to finalizing the review writing. FC and CS supervised the review writing and organization. All authors contributed to the article and approved the submitted version. 


\section{REFERENCES}

1. Sieper J, Poddubnyy D, Miossec P. The IL-23-IL-17 Pathway as a Therapeutic Target in Axial Spondyloarthritis. Nat Rev Rheumatol (2019) 15:747-57. doi: 10.1038/s41584-019-0294-7

2. Fossiez F, Djossou O, Chomarat P, Flores-Romo L, Ait-Yahia S, Maat C, et al. T Cell interleukin-17 Induces Stromal Cells to Produce Proinflammatory and Hematopoietic Cytokines. J Exp Med (1996) 183:2593-603. doi: 10.1084/ jem.183.6.2593

3. Aggarwal S, Gurney AL. Il-17: Prototype Member of an Emerging Cytokine Family. J Leukoc Biol (2002) 71:1-8.

4. Zrioual S, Ecochard R, Tournadre A, Lenief V, Cazalis MA, Miossec P. Genome-Wide Comparison Between IL-17A- and IL-17F-induced Effects in Human Rheumatoid Arthritis Synoviocytes. J Immunol (2009) 182:3112-20. doi: 10.4049/jimmunol.0801967

5. Cua DJ, Sherlock J, Chen Y, Murphy CA, Joyce B, Seymour B, et al. Interleukin-23 Rather Than interleukin-12 is the Critical Cytokine for Autoimmune Inflammation of the Brain. Nature (2003) 421:744-8. doi: 10.1038 /nature01355

6. Wilson NJ, Boniface K, Chan JR, McKenzie BS, Blumenschein WM, Mattson JD, et al. Development, Cytokine Profile and Function of Human Interleukin 17-Producing Helper T Cells. Nat Immunol (2007) 8:950-7. doi: 10.1038/ni1497

7. Sherlock JP, Taylor PC, Buckley CD, Cua DJ. Spondyloarthropathy: Interleukin 23 and Disease Modification. Lancet (2015) 385:2017-8. doi: 10.1016/S0140-6736(15)60970-9

8. Korn T, Bettelli E, Oukka M, Kuchroo VK. Il-17 and Th17 Cells. Annu Rev Immunol (2009) 27:485-517. doi: 10.1146/annurev.immunol.021908.132710

9. Korn T, Oukka M, Kuchroo V, Bettelli E. Th17 Cells: Effector T Cells With Inflammatory Properties. Semin Immunol (2007) 19:362-71. doi: 10.1016/ j.smim.2007.10.007

10. Noordenbos T, Blijdorp I, Chen S, Stap J, Mul E, Canete JD, et al. Human Mast Cells Capture, Store, and Release Bioactive, Exogenous IL-17A. J Leukoc Biol (2016) 100:453-62. doi: 10.1189/jlb.3HI1215-542R

11. Tamassia N, Arruda-Silva F, Calzetti F, Lonardi S, Gasperini S, Gardiman E, et al. A Reappraisal on the Potential Ability of Human Neutrophils to Express and Produce Il-17 Family Members In Vitro: Failure to Reproducibly Detect it. Front Immunol (2018) 9:795. doi: 10.3389/fimmu.2018.00795

12. Teng MW, Bowman EP, McElwee JJ, Smyth MJ, Casanova JL, Cooper AM, et al. Il-12 and IL-23 Cytokines: From Discovery to Targeted Therapies for Immune-Mediated Inflammatory Diseases. Nat Med (2015) 21:719-29. doi: 10.1038/nm.3895

13. Baeten D, Sieper J, Braun J, Baraliakos X, Dougados M, Emery P, et al. Secukinumab, an Interleukin-17A Inhibitor, in Ankylosing Spondylitis. $\mathrm{N}$ Engl J Med (2015) 373:2534-48. doi: 10.1056/NEJMoa1505066

14. van der Heijde D, Cheng-Chung Wei J, Dougados M, Mease P, Deodhar A, Maksymowych WP, et al. Ixekizumab, an interleukin-17A Antagonist in the Treatment of Ankylosing Spondylitis or Radiographic Axial Spondyloarthritis in Patients Previously Untreated With Biological Disease-Modifying AntiRheumatic Drugs (COAST-V): 16 Week Results of a Phase 3 Randomised, Double-Blind, Active-Controlled and Placebo-Controlled Trial. Lancet (2018) 392:2441-51. doi: 10.1016/S0140-6736(19)32971-X

15. Glatt S, Baeten D, Baker T, Griffiths M, Ionescu L, Lawson ADG, et al. Dual IL17A and IL-17F Neutralisation by Bimekizumab in Psoriatic Arthritis: Evidence From Preclinical Experiments and a Randomised Placebo-Controlled Clinical Trial That IL-17F Contributes to Human Chronic Tissue Inflammation. Ann Rheum Dis (2018) 77:523-32. doi: 10.1136/annrheumdis-2017-212127

16. Erdes S, Nasonov E, Kunder E, Pristrom A, Soroka N, Shesternya P, et al. Primary Efficacy of Netakimab, a Novel interleukin-17 Inhibitor, in the Treatment of Active Ankylosing Spondylitis in Adults. Clin Exp Rheumatol (2020) 38:27-34.

17. Ward MM, Deodhar A, Gensler LS, Dubreuil M, Yu D, Khan MA, et al. 2019 Update of the American College of Rheumatology/Spondylitis Association of America/Spondyloarthritis Research and Treatment Network Recommendations for the Treatment of Ankylosing Spondylitis and Nonradiographic Axial Spondyloarthritis. Arthritis Care Res (Hoboken) (2019) 71:1285-99. doi: 10.1002/acr.24025

18. McInnes IB, Mease PJ, Kirkham B, Kavanaugh A, Ritchlin CT, Rahman P, et al. Secukinumab, a Human anti-interleukin-17A Monoclonal Antibody, in Patients With Psoriatic Arthritis (FUTURE 2): A Randomised, Double-Blind,
Placebo-Controlled, Phase 3 Trial. Lancet (2015) 386:1137-46. doi: 10.1016/ S0140-6736(15)61134-5

19. Mease PJ, McInnes IB, Kirkham B, Kavanaugh A, Rahman P, van der Heijde $\mathrm{D}$, et al. Secukinumab Inhibition of Interleukin-17A in Patients With Psoriatic Arthritis. N Engl J Med (2015) 373:1329-39. doi: 10.1056/NEJMoa1412679

20. Coates LC, Wallman JK, McGonagle D, Schett GA, McInnes IB, Mease PJ, et al. Secukinumab Efficacy on Resolution of Enthesitis in Psoriatic Arthritis: Pooled Analysis of Two Phase 3 Studies. Arthritis Res Ther (2019) 21:266. doi: 10.1186/s13075-019-2055-z

21. Baraliakos X, Gossec L, Pournara E, Jeka S, Mera-Varela A, D’Angelo S, et al. Secukinumab in Patients With Psoriatic Arthritis and Axial Manifestations: Results From the Double-Blind, Randomised, Phase 3 MAXIMISE Trial. Ann Rheum Dis (2020) 80(5):582-90. doi: 10.1136/annrheumdis-2020-218808

22. Nash P, Kirkham B, Okada M, Rahman P, Combe B, Burmester GR, et al. Ixekizumab for the Treatment of Patients With Active Psoriatic Arthritis and an Inadequate Response to Tumour Necrosis Factor Inhibitors: Results From the 24-Week Randomised, Double-Blind, Placebo-Controlled Period of the SPIRIT-P2 Phase 3 Trial. Lancet (2017) 389:2317-27. doi: 10.1136/ annrheumdis-2017-eular.1576

23. Gladman DD, Orbai AM, Klitz U, Wei JC, Gallo G, Birt J, et al. Ixekizumab and Complete Resolution of Enthesitis and Dactylitis: Integrated Analysis of Two Phase 3 Randomized Trials in Psoriatic Arthritis. Arthritis Res Ther (2019) 21:38. doi: 10.1186/s13075-019-1831-0

24. Genovese MC, Mysler E, Tomita T, Papp KA, Salvarani C, Schwartzman S, et al. Safety of Ixekizumab in Adult Patients With Plaque Psoriasis, Psoriatic Arthritis and Axial Spondyloarthritis: Data From 21 Clinical Trials. Rheumatol (Oxford) (2020) 59(12):3834-44. doi: 10.1093/rheumatology/keaa189

25. Huang JX, Lee YH, Wei JC. Ixekizumab for the Treatment of Ankylosing Spondylitis. Expert Rev Clin Immunol (2020) 16(8):1-6. doi: 10.1080/ 1744666X.2020.1803063

26. Deodhar A, van der Heijde D, Gensler LS, Kim TH, Maksymowych WP, Ostergaard M, et al. Ixekizumab for Patients With non-Radiographic Axial Spondyloarthritis (COAST-X): A Randomised, Placebo-Controlled Trial. Lancet (2020) 395:53-64. doi: 10.1016/S0140-6736(19)32971-X

27. Torgutalp M, Poddubnyy D. Il-17 Inhibition in Axial Spondyloarthritis: Current and Future Perspectives. Expert Opin Biol Ther (2019) 19:631-41. doi: 10.1080/14712598.2019.1605352

28. Mease PJ, Helliwell PS, Hjuler KF, Raymond K, McInnes I. Brodalumab in Psoriatic Arthritis: Results From the Randomised Phase III AMVISION-1 and AMVISION-2 Trials. Ann Rheum Dis (2021) 80:185-93. doi: 10.1136/ annrheumdis-2019-216835

29. Liu S, Cui Y, Zhang X. Molecular Mechanisms and Clinical Studies of Iguratimod for the Treatment of Ankylosing Spondylitis. Clin Rheumatol (2020) 40(1):25-32. doi: 10.1007/s10067-020-05207-z

30. Luo $\mathrm{Y}$, Zheng $\mathrm{N}$, Wu R. Is Iguratimod Effective in Refractory Axial Spondyloarthritis? Scand J Rheumatol (2018) 47:518-20. doi: 10.1080/03009742.2017.1390150

31. Deodhar A, Gensler LS, Sieper J, Clark M, Calderon C, Wang Y, et al. Three Multicenter, Randomized, Double-Blind, Placebo-Controlled Studies Evaluating the Efficacy and Safety of Ustekinumab in Axial Spondyloarthritis. Arthritis Rheumatol (2019) 71:258-70. doi: 10.1002/art.40728

32. Segal BM, Constantinescu CS, Raychaudhuri A, Kim L, Fidelus-Gort R, Kasper LH. Repeated Subcutaneous Injections of IL12/23 p40 Neutralising Antibody, Ustekinumab, in Patients With Relapsing-Remitting Multiple Sclerosis: A Phase II, Double-Blind, Placebo-Controlled, Randomised, Dose-Ranging Study. Lancet Neurol (2008) 7:796-804. doi: 10.1016/S1474-4422(08)70173-X

33. Mease PJ, Gladman DD, Deodhar A, McGonagle DG, Nash P, Boehncke WH, et al. Impact of Guselkumab, an interleukin-23 p19 Subunit Inhibitor, on Enthesitis and Dactylitis in Patients With Moderate to Severe Psoriatic Arthritis: Results From a Randomised, Placebo-Controlled, Phase II Study. RMD Open (2020) 6:e001217. doi: 10.1136/rmdopen-2020-001217

34. van der Heijde D, Gensler LS, Deodhar A, Baraliakos X, Poddubnyy D, Kivitz A, et al. Dual Neutralisation of interleukin-17A and interleukin-17F With Bimekizumab in Patients With Active Ankylosing Spondylitis: Results From a 48-Week Phase IIb, Randomised, Double-Blind, Placebo-Controlled, Dose-Ranging Study. Ann Rheum Dis (2020) 79:595-604. doi: 10.1136/ annrheumdis-2020-216980

35. Mease PJ, Rahman P, Gottlieb AB, Kollmeier AP, Hsia EC, Xu XL, et al. Guselkumab in Biologic-Naive Patients With Active Psoriatic Arthritis 
(DISCOVER-2): A Double-Blind, Randomised, Placebo-Controlled Phase 3 Trial. Lancet (2020) 395:1126-36. doi: 10.1016/S0140-6736(20)30263-4

36. Gordon KB, Strober B, Lebwohl M, Augustin M, Blauvelt A, Poulin Y, et al. Efficacy and Safety of Risankizumab in Moderate-to-Severe Plaque Psoriasis (UltIMMa-1 and UltIMMa-2): Results From Two Double-Blind, Randomised, Placebo-Controlled and Ustekinumab-Controlled Phase 3 Trials. Lancet (2018) 392:650-61. doi: 10.1016/S0140-6736(18)31713-6

37. Baeten D, Ostergaard M, Wei JC, Sieper J, Jarvinen P, Tam LS, et al. Risankizumab, an IL-23 Inhibitor, for Ankylosing Spondylitis: Results of a Randomised, Double-Blind, Placebo-Controlled, Proof-of-Concept, DoseFinding Phase 2 Study. Ann Rheum Dis (2018) 77:1295-302. doi: 10.1136/ annrheumdis-2018-213328

38. Mease P. Ustekinumab Fails to Show Efficacy in a Phase Iii Axial Spondyloarthritis Program: The Importance of Negative Results. Arthritis Rheumatol (2019) 71:179-81. doi: 10.1002/art.40759

39. Siebert S, McGucken A, McInnes IB. The IL-23/IL-17A Axis in Spondyloarthritis: Therapeutics Informing Pathogenesis? Curr Opin Rheumatol (2020) 32:349-56. doi: 10.1097/BOR.0000000000000719

40. Ruiz de Morales JMG, Puig L, Dauden E, Canete JD, Pablos JL, Martin AO, et al. Critical Role of Interleukin (IL)-17 in Inflammatory and Immune Disorders: An Updated Review of the Evidence Focusing in Controversies. Autoimmun Rev (2020) 19:102429. doi: 10.1016/j.autrev.2019.102429

41. Goepfert A, Lehmann S, Blank J, Kolbinger F, Rondeau JM. Structural Analysis Reveals That the Cytokine Il-17f Forms a Homodimeric Complex With Receptor Il-17RC to Drive Il-17ra-Independent Signaling. Immunity (2020) 52:499-512.e5. doi: 10.1016/j.immuni.2020.02.004

42. Chen S, Blijdorp IC, van Mens LJJ, Bowcutt R, Latuhihin TE, van de Sande MGH, et al. Interleukin 17A and IL-17F Expression and Functional Responses in Rheumatoid Arthritis and Peripheral Spondyloarthritis. J Rheumatol (2020) 47(11):1606-13. doi: 10.3899/jrheum.190571

43. Gossec L, Baraliakos X, Kerschbaumer A, de Wit M, McInnes I, Dougados M, et al. EULAR Recommendations for the Management of Psoriatic Arthritis With Pharmacological Therapies: 2019 Update. Ann Rheum Dis (2020) 79:700-12. doi: 10.1136/annrheumdis-2020-218456

44. van der Heijde D, Ramiro S, Landewe R, Baraliakos X, Van den Bosch F, Sepriano A, et al. 2016 Update of the ASAS-EULAR Management Recommendations for Axial Spondyloarthritis. Ann Rheum Dis (2017) 76:978-91. doi: 10.1136/annrheumdis-2016-210770

45. Menegatti S, Bianchi E, Rogge L. Anti-Tnf Therapy in Spondyloarthritis and Related Diseases, Impact on the Immune System and Prediction of Treatment Responses. Front Immunol (2019) 10:382. doi: 10.3389/fimmu.2019.00382

46. Deodhar A, Gensler LS, Kay J, Maksymowych WP, Haroon N, Landewe R, et al. A Fifty-Two-Week, Randomized, Placebo-Controlled Trial of Certolizumab Pegol in Nonradiographic Axial Spondyloarthritis. Arthritis Rheumatol (2019) 71:1101-11. doi: 10.1002/art.40866

47. Dougados M, van der Heijde D, Sieper J, Braun J, Citera G, Lenaerts J, et al. Effects of Long-Term Etanercept Treatment on Clinical Outcomes and Objective Signs of Inflammation in Early Nonradiographic Axial Spondyloarthritis: 104Week Results From a Randomized, Placebo-Controlled Study. Arthritis Care Res (Hoboken) (2017) 69:1590-8. doi: 10.1002/acr.23276

48. Rudwaleit M, Rosenbaum JT, Landewe R, Marzo-Ortega H, Sieper J, van der Heijde D, et al. Observed Incidence of Uveitis Following Certolizumab Pegol Treatment in Patients With Axial Spondyloarthritis. Arthritis Care Res (Hoboken) (2016) 68:838-44. doi: 10.1002/acr.22848

49. Lindstrom U, Glintborg B, Di Giuseppe D, Nordstrom D, Aarrestad Provan S, Gudbjornsson B, et al. Treatment Retention of Infliximab and Etanercept Originators Versus Their Corresponding Biosimilars: Nordic Collaborative Observational Study of 2334 Biologics Naive Patients With Spondyloarthritis. RMD Open (2019) 5:e001079. doi: 10.1136/rmdopen-2019-001079

50. Yang L, Fanok MH, Mediero-Munoz A, Fogli LK, Corciulo C, Abdollahi S, et al. Augmented Th17 Differentiation Leads to Cutaneous and SynovioEntheseal Inflammation in a Novel Model of Psoriatic Arthritis. Arthritis Rheumatol (2018) 70:855-67. doi: 10.1002/art.40447

51. Gracey E, Hromadova D, Lim M, Qaiyum Z, Zeng M, Yao Y, et al. TYK2 Inhibition Reduces Type 3 Immunity and Modifies Disease Progression in Murine Spondyloarthritis. J Clin Invest (2020) 130:1863-78. doi: 10.1172/JCI126567

52. van der Heijde D, Deodhar A, Wei JC, Drescher E, Fleishaker D, Hendrikx T, et al. Tofacitinib in Patients With Ankylosing Spondylitis: A Phase II, 16-
Week, Randomised, Placebo-Controlled, Dose-Ranging Study. Ann Rheum Dis (2017) 76:1340-7. doi: 10.1136/annrheumdis-2016-210322

53. van der Heijde D, Song IH, Pangan AL, Deodhar A, van den Bosch F, Maksymowych WP, et al. Efficacy and Safety of Upadacitinib in Patients With Active Ankylosing Spondylitis (SELECT-AXIS 1): A Multicentre, Randomised, Double-Blind, Placebo-Controlled, Phase 2/3 Trial. Lancet (2019) 394:2108-17. doi: 10.1016/S0140-6736(19)32534-6

54. van der Heijde D, Baraliakos X, Gensler LS, Maksymowych WP, Tseluyko V, Nadashkevich O, et al. Efficacy and Safety of Filgotinib, a Selective Janus Kinase 1 Inhibitor, in Patients With Active Ankylosing Spondylitis (TORTUGA): Results From a Randomised, Placebo-Controlled, Phase 2 Trial. Lancet (2018) 392:2378-87. doi: 10.1016/S0140-6736(18)32463-2

55. Sherlock JP, Joyce-Shaikh B, Turner SP, Chao CC, Sathe M, Grein J, et al. Il-23 Induces Spondyloarthropathy by Acting on ROR-gammat+ Cd3+Cd4-CD8Entheseal Resident T Cells. Nat Med (2012) 18:1069-76. doi: 10.1038/nm.2817

56. Vecellio M, Hake VX, Davidson C, Carena MC, Wordsworth BP, Selmi C. The IL-17/IL-23 Axis and Its Genetic Contribution to Psoriatic Arthritis. Front Immunol (2020) 11:596086. doi: 10.3389/fimmu.2020.596086

57. Brown MA, Kenna T, Wordsworth BP. Genetics of Ankylosing SpondylitisInsights Into Pathogenesis. Nat Rev Rheumatol (2016) 12:81-91. doi: 10.1038/ nrrheum.2015.133

58. Gravallese EM, Schett G. Effects of the IL-23-IL-17 Pathway on Bone in Spondyloarthritis. Nat Rev Rheumatol (2018) 14:631-40. doi: 10.1038/s41584018-0091-8

59. Pathan E, Abraham S, Van Rossen E, Withrington R, Keat A, Charles PJ, et al. Efficacy and Safety of Apremilast, an Oral Phosphodiesterase 4 Inhibitor, in Ankylosing Spondylitis. Ann Rheum Dis (2013) 72:1475-80. doi: 10.1136/ annrheumdis-2012-201915

60. Feld J, Ye JY, Chandran V, Inman RD, Haroon N, Cook R, et al. Is Axial Psoriatic Arthritis Distinct From Ankylosing Spondylitis With and Without Concomitant Psoriasis? Rheumatol (Oxford) (2020) 59:1340-6. doi: 10.1093/rheumatology/kez457

61. Jadon DR, Sengupta R, Nightingale A, Lindsay M, Korendowych E, Robinson G, et al. Axial Disease in Psoriatic Arthritis Study: Defining the Clinical and Radiographic Phenotype of Psoriatic Spondyloarthritis. Ann Rheum Dis (2017) 76:701-7. doi: 10.1136/annrheumdis-2016-209853

62. Hueber W, Sands BE, Lewitzky S, Vandemeulebroecke M, Reinisch W, Higgins PD, et al. Secukinumab, a Human anti-IL-17A Monoclonal Antibody, for Moderate to Severe Crohn's Disease: Unexpected Results of a Randomised, Double-Blind Placebo-Controlled Trial. Gut (2012) 61:1693700. doi: 10.1136/gutjnl-2011-301668

63. Targan SR, Feagan B, Vermeire S, Panaccione R, Melmed GY, Landers C, et al. Double-Blind, Placebo-Controlled Phase 2 Study of Brodalumab in Patients With Moderate-to-Severe Crohn's Disease. Am J Gastroenterol (2016) 111:1599-607. doi: 10.1038/ajg.2016.298

64. Schreiber S, Colombel JF, Feagan BG, Reich K, Deodhar AA, McInnes IB, et al. Incidence Rates of Inflammatory Bowel Disease in Patients With Psoriasis, Psoriatic Arthritis and Ankylosing Spondylitis Treated With Secukinumab: A Retrospective Analysis of Pooled Data From 21 Clinical Trials. Ann Rheum Dis (2019) 78:473-9. doi: 10.1136/annrheumdis-2018-214273

65. Egeberg A, Mallbris L, Warren RB, Bachelez H, Gislason GH, Hansen PR, et al. Association Between Psoriasis and Inflammatory Bowel Disease: A Danish Nationwide Cohort Study. Br J Dermatol (2016) 175:487-92. doi: 10.1111/bjd.14528

66. Braun J, Baraliakos X, Listing J, Davis J, van der Heijde D, Haibel H, et al. Differences in the Incidence of Flares or New Onset of Inflammatory Bowel Diseases in Patients With Ankylosing Spondylitis Exposed to Therapy With Anti-Tumor Necrosis Factor Alpha Agents. Arthritis Rheum (2007) 57:63947. doi: 10.1002/art.22669

Conflict of Interest: The authors declare that the research was conducted in the absence of any commercial or financial relationships that could be construed as a potential conflict of interest.

Copyright $\odot 2021$ Ceribelli, Motta, Vecellio, Isailovic, Ciccia and Selmi. This is an openaccess article distributed under the terms of the Creative Commons Attribution License (CC BY). The use, distribution or reproduction in other forums is permitted, provided the original author(s) and the copyright owner(s) are credited and that the original publication in this journal is cited, in accordance with accepted academic practice. No use, distribution or reproduction is permitted which does not comply with these terms. 